\title{
SOFOSBUVIR-VELPATASVIR THERAPY IN THE TREATMENT OF CHRONIC HEPATITIS C GENOTYPE 3
}

\author{
Arif Qayyum Khan, Hala Mansoor, Samina Fida, Saba Saif, Javed Iqbal, Muhammad Siddique \\ Combined Military Hospital Lahore Medical College and Institute of Dentistry Lahore/National University of Medical Sciences (NUMS) \\ Pakistan
}

\begin{abstract}
Objective: To determine the efficacy and safety of sofosbuvir-velpatasvir combination therapy in treatment of chronic hepatitis $\mathrm{C}$ genotype 3 .

Study Design: Prospective cohort study.

Place and Duration of Study: Department of Medicine, Combined Military Hospital Lahore, from Mar 2018 to Oct 2019.

Methodology: Eighty eight consecutive patients, who were $\geq 18$ years of age with chronic hepatitis $C$ as confirmed by polymerase chain reaction were included in the study. Primary end point was sustained virological response at 12 week post-treatment. Patients with any of the following criteria at presentation were excluded from study: aspartate/alanine aminotransferase $>10$ times the upper limit of normal, total bilirubin twice the upper limit of normal, haemoglobin $<8 \mathrm{~g} / \mathrm{dL}$, platelet count $<30,000 / \mathrm{uL}$, albumin $<2 \mathrm{~g} / \mathrm{dL}$ and creatinine clearance of $<60 \mathrm{~mL} /$ min. Additional criteria for exclusion included patients who had co-infection with hepatitis B or human immune deficiency virus (HIV), significant cardiac or lung disease, porphyria, liver cirrhosis caused by non-HCV related causes or co-existent hepatocellular carcinoma.

Results: Overall sustained virological response was achieved in 82 of 84 patients (97.6\%). One of the patients with genotype 3 had detectable HCV RNA at end of treatment, which became undetectable at 12 weeks, post-treatment. 38 /38 (100\%) patients without cirrhosis while 41/43 patients (95.3\%) with compensated cirrhosis and 3/3 with decompensated cirrhosis achieved sustained virological response. Two (2.3\%) patients had on-treatment virological failure. Four patients were lost to follow up.

Conclusion: Treatment with sofosbuvir and velpatasvir is effective and well tolerated in patients with chronic hepatitis $\mathrm{C}$, genotype 3 .
\end{abstract}

Keywords: Hepatitis C, Sustained virological response, Sofosbuvir, Velpatasvir.

This is an Open Access article distributed under the terms of the Creative Commons Attribution License (http://creativecommons.org/licenses/by/4.0), which permits unrestricted use, distribution, and reproduction in any medium, provided the original work is properly cited.

\section{INTRODUCTION}

Hepatitis remains a global health challenge, with an enormous 328 million people being affected with hepatitis B or C1. In 2013, The Global Burden of Disease Study reported a major surge in hepatitis related mortality to 1.45 million global deaths from that of 0.89 million in 1990. The highest burden of mortality of $52 \%$ was noted from South and East Asia which was highest in absolute numbers, as well2. In 2016, World Health Assembly passed a resolution to take measures to abolish liver disease due to hepatitis B and C as a threat to public health by the year 2030. In 2017, in the global hepatitis report by World Health

Correspondence: Dr Hala Mansoor, Dept of Medicine, CMH Lahore Medical College and Institute of Dentistry Lahore Pakistan Received: 20 May 2020; revised received: 28 Jun 2020; accepted: 23 Jul 2020
Organization, it was noted that in year 2015; globally 720,000 deaths were due to various complications of advanced chronic liver disease whereas 470,000 were related to hepatocellular carcinoma ${ }^{1}$. An estimated $11.55 \%$ of the adult Pakistani population is affected by hepatitis C, of which upto $91.8 \%$ have genotype $3 \mathrm{a}^{3}$. Another study from Pakistan, which showed a dismal average survival of only 23.9 months for patients presenting with hepatocellular carcinoma, revealed $84.4 \%$ had evidence of hepatitis C infection ${ }^{4}$.

Direct acting antiviral agents (DAAs) have transformed therapeutic outlook of patients with chronic hepatitis C-7. Sofosbuvir, an NS5B polymerase inhibitor, and velpatasvir which is NS5A inhibitor, are approved in combination for the treatment of all genotypes of hepatitis Cranging 
from 1-6. This combination therapy is highly efficacious, and in phase 3 clinical trials have achieved sustained virological response at 12 weeks (SVR 12) of 98\% in genotypes 1-68-10.

Hereby we report our experience of treating the patients having hepatitis $\mathrm{C}$, genotype 3 , with sofosbuvir and velpatasvir.

\section{METHODOLOGY}

This prospective cohort study was conducted at Combined Military Hospital Lahore from March 2018 to October 2019 in lines with the principles of Helsinki's declaration and was approved by institution's ethics committee (ref. 447/ERC/ CMHLMC). A minimum sample size of 73 patients was calculated by the Australian Bureau of Statistics online sample size calculator, assuming $95 \%$ confidence interval and 5\% margin of error, using the $95 \%$ response rate in patients with genotype 3 , in the study by Foster, et al as a reference ${ }^{10}$.

A total number of 88 patients were enrolled using non-probability consecutive sampling technique. Inclusion criterias were; documented evidence of hepatitis $\mathrm{C}$ infection with HCV RNA above the threshold of quantification by polymerase chain reaction (PCR) and $\geq 18$ years of age. All patients were infected with genotype 3 with either no cirrhosis, compensated cirrhosis (Fibroscan with $\mathrm{kPa}>12.5$ or an aspartate aminotransferase: platelet ratio index $>2$ ) or decompensated cirrhosis. Patients with any of the following criteria at presentation were excluded from study: aspartate aminotransferase (AST) $>10$ times the upper limit of normal (ULN), Alanine aminotransferase $(\mathrm{ALT})>10$ times the upper limit of normal, total bilirubin $>2$ ULN, haemoglobin $<8$ $\mathrm{g} / \mathrm{dL}$, platelet count $<30,000 / \mathrm{uL}$, albumin $<2 \mathrm{~g} /$ $\mathrm{dL}$ and creatinine clearance as calculated by Cockcroft - Gaultformula, of $<60 \mathrm{~mL} / \mathrm{min}$. Additional criteria for exclusion included patients who had co-infection with hepatitis B or human immune deficiency virus (HIV), significant cardiac or lung disease, porphyria, liver cirrhosis caused by non-HCV related causes (Wilson's disease, alcohol, hemochromatosis, cholangitis or alpha one antitrypsin deficiency) or co-existent hepatocellular carcinoma.

All patients received velpatasvir $100 \mathrm{mg}$ and sofosbuvir $400 \mathrm{mg}$ for 12 weeks.

Cirrhosis was documented by consistent clinical, haematological (reduced platelet count and raised INR), biochemical (low albumin, raised bilirubin and AST>ALT), fibroscan score of $>12.5$ or by an APRI score of $>2$ with nodular liver, heterogeneous hepatic parenchyma with irregular margins on ultrasound or by signs of portal hypertension or liver decompensation like dilated portal veins, ascites, collaterals or splenomegaly. Fibroscan was offered to all patients except for the patients with decompensated liver cirrhosis, to determine extent of hepatic fibrosis. However, 71 patients got it done by a single operator with Echosens 530 compact. Out of these $71 ; 43(60.56 \%)$ had fibroscan score of $>12.5 \mathrm{kPa}$, while $28(39.43 \%)$ had $<12.5 \mathrm{kPa}$. HCV genotype and subtypes were ascertained. Outpatient clinic visits were scheduled at the end of weeks 4,8,12 of treatment and at week 4 and 12 post-treatment. Patients were followed up for safety as well as evaluation of any adverse reactions, by clinical examination, vital monitoring and laboratory testing.

The primary efficacy end point was sustained virological response, defined as HCV RNA negativity at 12 weeks post treatment (SVR 12)11. End of treatment response (ETR) was defined as undetectable HCV RNA, at the end of therapy, while RVR (rapid virological response) was defined as undetectable HCV RNA at 4 weeks ${ }^{11}$. The safety and efficacy analysis was performed for all patients, even if they discontinued the treatment untimely. Data analysis was done by using SPSS version 25 for windows. The relationship between virological response and different parameters such as status of the liver (cirrhosis or no cirrhosis) as well as the treatment status (treatment naïve or experienced) was calculated using the Pearson's correlation.

Descriptive statistics of qualitative variables were presented as frequency and percentages, 
while those of quantitative variables expressed as mean and standard deviation.

\section{RESULTS}

In total 88 patients, with chronic hepatitis C, $52(59.1 \%)$ females were followed to determine treatment outcomes. Female were in majority with a number of $52(59.1 \%)$, while mean age of the patients was 45.7 and range $18-85$ years. Most of the patients were solely infected with hepatitis C genotype 3, 86 (97.7\%), while 2 patients had dual infection with both genotypes 1 and 3 (2.3\%). Thirty eight (43.2\%) had no cirrhosis, 47 $(53.4 \%)$ compensated and 3 patients $(3.4 \%)$ had decompensated cirrhosis. Both patients, who had dual infection with genotype 1 and 3, did not

Table-I: Demographics and baseline characteristics.

\begin{tabular}{|c|c|}
\hline & $n=88(\%)$ \\
\hline Mean age, years (range) & $45.7(18-85)$ \\
\hline Female, n (\%) & $52(59.1)$ \\
\hline \multicolumn{2}{|l|}{ Hepatitis C virus genotypes, $\mathrm{n}(\%)$} \\
\hline $1 \& 3$ & $2(2.3)$ \\
\hline 3 & $86(97.7)$ \\
\hline $\begin{array}{l}\text { Alanine aminotransferase }>1.5 \times \\
\text { upper limit of normal, } \mathrm{n}(\%)\end{array}$ & $48(54.54)$ \\
\hline $\begin{array}{l}\text { Mean baseline Hepatitis C virus } \\
\text { ribonucleic acid, log } 10 \mathrm{IU} / \mathrm{ml} \\
\text { (range) }\end{array}$ & $6.54(3-7.43)$ \\
\hline $\begin{array}{l}\text { Hepatitis C virus ribonucleic } \\
\text { acid } \geq 800,000 \mathrm{IU} / \mathrm{ml}, \mathrm{n}(\%)\end{array}$ & $46(52 \%)$ \\
\hline \multicolumn{2}{|l|}{ Cirrhosis, n (\%) } \\
\hline Compensated cirrhosis & $47(53.4)$ \\
\hline Decompensated cirrhosis & $3(3.4)$ \\
\hline \multicolumn{2}{|c|}{ Prior Hepatitis C virus treatment, $\mathrm{n}(\%)$} \\
\hline Standard interferon-ribavirin & $1(1.1)$ \\
\hline Pegylated interferon-ribavirin & $3(3.4)$ \\
\hline Sofosbuvir-ribavirin & $3(3.4)$ \\
\hline $\begin{array}{l}\text { Pegylated interferon-ribavirin } \\
\text { followed by Sofosbuvir- } \\
\text { ribavirin }\end{array}$ & $2(2.3)$ \\
\hline \multicolumn{2}{|c|}{$\begin{array}{l}\text { Response to previous Hepatitis C virus treatment, } \\
\text { n (\%) }\end{array}$} \\
\hline No response & $5(5.7)$ \\
\hline Relapse & $4(4.5)$ \\
\hline
\end{tabular}

have cirrhosis. Among 88 enrolled patient, 79 were treatment naïve, while 9 were treatment experienced (1 with standard interferon-ribavirin,
3 with pegylated IF-ribavirin, 3 with sofosbuvirribavirin and two were treated twice before; first with pegylated IF-ribavirin and later with sofosbuvir-ribavirin) (table-I). All patients received $400 \mathrm{mg}$ of sofosbuvir and $100 \mathrm{mg}$ of velpatasvir for 12 weeks. Two patients had leucocytoclastic vasculitis at baseline, before start of treatment.

\section{Antiviral Response}

At the 4th week of treatment RVR was achieved in 82 of 88 patients (93\%), including two patients with genotype 1 and 3 dual infection. Four patients were lost to follow up. ETR was noted in $81 / 84$ of patients $(96.4 \%)$. Overall SVR 12 was achieved by 82 of 84 patients (97.6\%), including patients with dual infection with genotype 1 and 3. One of the patients with genotype 3 , whose HCV RNA was detectable at end of treatment, had undetectable HCV RNA after 12 weeks

Table-II: Overall response to treatment.

\begin{tabular}{|c|c|}
\hline & $\mathrm{n}=88^{*}(\%)$ \\
\hline \multicolumn{2}{|c|}{$\begin{array}{l}\text { Hepatitis C virus ribonucleic acidbelow the limit } \\
\text { of quantification, during treatment }\end{array}$} \\
\hline Week 4 & $82 / 88(93)$ \\
\hline Treatment naïve & $74 / 79(93.7)$ \\
\hline Treatment experienced & $8 / 9(88.9)$ \\
\hline Overall response week 12 & $81 / 84(96.4)$ \\
\hline Treatment naïve & $73 / 75(97.3)$ \\
\hline Treatment experienced & $8 / 9(88.9)$ \\
\hline \multicolumn{2}{|c|}{$\begin{array}{l}\text { Hepatitis } C \text { virus ribonucleic acid below the limi } \\
\text { of quantification, after treatment }\end{array}$} \\
\hline $\begin{array}{l}12 \text { weeks, post treatment (Sus- } \\
\text { tained virological response } 12 \text { ) }\end{array}$ & $82 / 84(97.6)$ \\
\hline \multicolumn{2}{|l|}{ By Cirrhosis Status } \\
\hline Yes & $44 / 46(95.7)$ \\
\hline No & $38 / 38(100)$ \\
\hline \multicolumn{2}{|l|}{ By Treatment Status } \\
\hline Treatment naïve & $73 / 75$ (97.3) \\
\hline Treatment experienced & $9 / 9(100)$ \\
\hline $\begin{array}{l}\text { Virological failure during } \\
\text { treatment }\end{array}$ & $2 / 88(2.3)$ \\
\hline
\end{tabular}

of finishing treatment. This was a 45 year-old gentleman with compensated cirrhosis, who had previously been non-responder to treatment with sofosbuvir and ribavirin. 38/38 (100\%) patients without cirrhosis achieved SVR 12. Of the 50 patients with cirrhosis, $41 / 43$ patients $(95.3 \%)$ 
with compensated cirrhosis achieved SVR 12, while 4 patients as already mentioned above were lost to follow up. Whereas all 3/3 (100\%) patients with decompensated cirrhosis achieved SVR 12 (table-II).

Subgroup analysis of 71 patients according to fibrosis score was also done. 28/28 (100\%) patients whose fibroscan score was $<12.5 \mathrm{kPa}$ achieved SVR 12, while 20/21 (95\%) patients with $\mathrm{kPa}$ of $>12.5-25,11 / 11$ (100\%) with $\mathrm{kPa}$ of $>25-50$ and $6 / 7(85.7 \%)$ with $\mathrm{kPa}>50-75$ achieved SVR $(p=0.17)$. Four patients were lost to follow up.

Further exploration of the data was done and ROC curves were generated to assess the relationship of fibrosis score with minimal SVR. The value of fibrosis score at which the lowest SVR 12 was observed with maximum sensitivity was $24.150 \mathrm{kPa}$, corresponding to area under the curve (AUC) of 0.826 (figure).

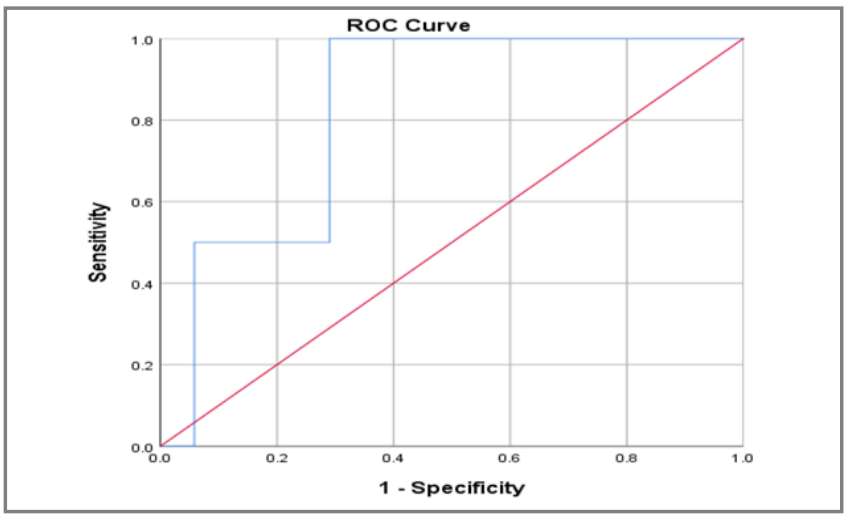

Figure: ROC curve of fibrosis score with SVR 12.

A total of 2 patients $(2.3 \%)$ had on-treatment virological failure. Both of these patients were treatment naïve, had compensated liver cirrhosis caused by genotype 3 infection with high viral load (HCV RNA $>800,000 \mathrm{IU} / \mathrm{ml}$ ). One of the patient had a fibroscan score of $24.6 \mathrm{kPa}$ and the other had $59.5 \mathrm{kPa}$. Resistance testing could not be done due to non-availability (table-III).

\section{Safety}

Overall the treatment was very well tolerated. Most frequent adverse effects which were reported by the patients included fatigue, irrita- bility, nausea and headaches by $7 / 88$ (8\%) patients. Three patients $(3.4 \%)$ developed hemoglobin drop of $>2 \mathrm{~g} / \mathrm{dl}$ during treatment. None of the patients required blood transfusion. During treatment, none of the patients had significant hepatic decompensation or hyperbilirubinemia of $>2.5 \mathrm{mg} / \mathrm{dl}$.In one patient $(1.1 \%)$ platelet count dropped to 44,000 per $\mathrm{mm}^{3}$ at the $12^{\text {th }}$ week of treatment, from a pretreatment value of 90,000 per $\mathrm{mm}^{3}$. However, patient did not experience any abnormal bleeding and platelet count subsequently improved to 70,000 per $\mathrm{mm}^{3}$ at 12 th week post treatment and later to 85,000 per $\mathrm{mm}^{3}$ at 48th week.

Leucocytoclastic vasculitis, noted in two

Table-III: Response to treatment according to fibroscan based kilopascal scoring.

\begin{tabular}{|c|c|c|c|}
\hline $\begin{array}{l}\text { Kilopascal } \\
\text { scoring }\end{array}$ & $\begin{array}{c}\text { End of } \\
\text { treatment } \\
\text { response } \\
\text { achieved } \\
n(\%)\end{array}$ & $\begin{array}{l}\text { Sustained } \\
\text { virological } \\
\text { response } \\
\text { achieved } \\
n(\%)\end{array}$ & $\begin{array}{c}\text { Lost } \\
\text { to } \\
\text { follow } \\
\text { up } \\
\text { n }(\%)^{*}\end{array}$ \\
\hline \multicolumn{4}{|c|}{ Non-cirrhotic, $n=28$} \\
\hline$<12.5$ & $28(100)$ & $28(100)$ & - \\
\hline \multicolumn{4}{|c|}{ Mild to moderate cirrhosis, $n=22$} \\
\hline$>12.5-25$ & $20(95)$ & $20(95)$ & 1 \\
\hline \multicolumn{4}{|c|}{ Moderately advanced cirrhosis, $n=13$} \\
\hline$>25-50$ & $11(100)$ & $11(100)$ & 2 \\
\hline \multicolumn{4}{|c|}{ Advanced cirrhosis, $n=8$} \\
\hline$>50-75$ & $5(71.4)$ & $6(85.7)$ & 1 \\
\hline
\end{tabular}

patients at baseline improved with treatment.

\section{DISCUSSION}

The efficacy and safety of sofosbuvir-velpatasvir therapy in patients with hepatitis C, is well proven, with numerous studies showing excellent outcome in all genotypes of hepatitis $\mathrm{C}$, however studies from our part of the world, which carries the highest burden of hepatitis are lacking7,9,11. In this study sofosbuvir-velpatasvir were safe and effective for treatment of patients with hepatitis $\mathrm{C}$, genotype 3 in our local population. The superb overall response of SVR 12 (97.6\%) was maintained across various categories of patient regardless of the fact whether they were treatment 
naive or had prior treatment of ribavirin in combination with either of standard interferon, pegylated interferon or sofosbuvir. About 100\% of patients without cirrhosis and $95.3 \%$ with cirrhosis achieved SVR 12, however it did not reach the statistical significance $(p=0.83)$. These findings are consistent with the literature. ASTRAL-3 had shown almost similar results with SVR 12 of $91 \%$ in patients with cirrhosis, while in those without cirrhosis it was $97 \%{ }^{10}$. In decompensated cirrhosis, although an SVR 12 of 100\% (3/3) was noted in our study, which is in contrast to the previous studies (ASTRAL 4) which showed SVR 12 of $50 \% 12$. However there were only $3.4 \%$ of patients with decompensated liver cirrhosis in our study. In 2016, Agarwal et al performed post-hoc analysis of ASTRAL studies (ASTRAL1, ASTRAL2 and ASTRAL3) involving 1035 patients. This analysis again strengthened the efficacy of 12 weeks of sofosbuvir-velpatasvir combination with overall SVR 12 of $98 \%$ across all genotypes and 95\% (264 /277) in genotype 3 . However, there were 11 relapses in genotype 3 and only 2 in genotype- $1^{13}$.

Subgroup analysis of patients based upon fibroscan parameters, as mentioned in results, showed that SVR 12 rates were better in patients with low fibrosis score. In 2017, Lawitz, et al reported similar outcomes when they performed integrated retrospective analysis of ASTRAL and POLARIS trials to find out the efficacy of 12 weeks of sofosbuvir-velpatasvir according to fibrosis stage. Although in genotype 3, the overall response was good across the study population, it fell with increasing fibrosis score. So, $98.6 \%$ (218/ 221) with F0/F2 fibrosis; 99.1\% (232/234) with F3 while 97.2\% (431/443) achieved SVR1214. The sofosbuvir-velpatasvir treatment has been extensively reviewed in an excellent 2018 article by Zignego, et al. This further endorsed the fact that this treatment is highly efficacious in treatment naïve chronic hepatitis $C$ patients without cirrhosis, with SVR 12 approaching 100\%, while in those with decompensated cirrhosis, it can be improved to $94 \%$ with addition of ribavirin ${ }^{15}$. A fairly recent study from Pakistan by Butt, et al has reported almost similar results to our study with
SVR 12 of $90.5 \%(86 / 95)$ in patients without cirrhosis and $92.1 \%(35 / 38)$ in patients with compensated cirrhosis ${ }^{16}$.

In patients with cirrhosis, regression of liver fibrosis has been noted after successful treatment of hepatitis $C$ but does different grades of advanced fibrosis scoring on fibroscan, ranging from 12.5 to $75 \mathrm{kPa}$ (all of which is considered F4), has implications on choice of therapy is still unclear 7,17 .

In 2012 study by Castera, et al did a comprehensive review to find optimal the optimal value of liver stiffness associated with high hepatic venous pressure gradient (HVPG $\geq 10$ ). It was noted that $\mathrm{kPa}$ value of 13.6 had area under curve (AUC) of 0.99 with $97 \%$ sensitivity and $92 \%$ specificity ${ }^{18}$. While Bureau, et al reported the optimal cut off of liver stiffness, associated with HVPG $\geq 10$ to be $21 \mathrm{kPa}$ with (AUC) of $0.94^{19}$. In 2006, Kazemi, et al reported that liver stiffness $<19 \mathrm{kPa}$ is predictive of absence of $\geq$ grade II of oesophageal varices with sensitivity of $84 \%$ and positive predictive value of $47 \% 20$.

Based on above mentioned studies with evidence of endoscopic findings of increased frequency of esophageal varices or high HVPG with increasing fibrosis, arbitrarily, sub classifying cirrhotic patients with F4 fibrosis, into mild to moderate (fibroscan score of 12.5 to $25 \mathrm{kPa}$ ), moderately advanced (fibroscan score of 25 to 50 $\mathrm{kPa}$ ) and advanced cirrhosis (fibroscan score of 50 to $75 \mathrm{kPa}$ ); should be considered. However it requires further evaluation and correlation with liver biopsies in large prospective studies.

Sofosbuvir-velpatasvir combination treatment was well tolerated in our patients and side effects were generally mild with no mortality. This is in keeping with literature. A 2016, safety analysis of sofosbuvir-velpatasvir by Shiffman et $a l$, reported excellent tolerability of this combination with almost similar incidence of minor adverse events in treatment versus control arm. Three percent of the patients had grade 3 or 4 adverse events, while serious adverse events 
occurred in $2 \%$ of patients versus none in control $\operatorname{arm}^{21}$.

Limitations of this study include the singlearm, small sample size, open-label design and lack of resistance testing to detect NS5A resistance-associated substitutions (RAS) either at the baseline or at the time of virological failure. Similarly for patients who, had virological failure or relapse after previous treatment with sofosbuvir, NS5B-RAS or the status of IL28 B genotype could not be determined due to non-availability. Studies have shown that as many as $8.5 \%$ of patients with genotype 3 may have NS5A-RAS, while that of NS5B-RAS is about $<4 \%$, which rises with recurrent treatment and reduces rate of virological clearance 22-24. Although following the results of POLARIS-4 trial, current AASLD guidelines do not recommend sofosbuvir-velpatasvir combination, in patients with genotype 3, who had previous treatment with sofosbuvir; the patients in our study were treated according to the AASLD guidelines prevalent at the time of study ${ }^{25}$. In addition, all 5 relapsers after the previous sofosbuvir-ribavirin treatment had cirrhosis and there was no other treatment option available. All five of these patients achieved SVR 12, although in one patient, 4 week PCR was negative, and ETR was again positive, but again at 12 weeks posttreatment it turned negative. Also the study population was not uniform with $79(89.77 \%)$, being treatment naïve and $9(10.22 \%)$ were treatment experienced.

\section{CONCLUSION}

Treatment with sofosbuvir and velpatasvir is effective and well tolerated in patients with hepatitis $C$ genotype 3 , with low rates of virological failure. However, the laboratory facility of resistance-associated substitutions should be freely available at affordable prices in countries which carry a high global burden of infectionfor effective treatment of difficult to treat patients, if the aim of hepatitis eradication is to be materialized.

\section{CONFLICT OF INTEREST}

This study has no conflict of interest to be declared by any author.

\section{REFERENCES}

1. World Health Organization. Global hepatitis report Geneva. 2017. Available from: http://www.who.int/hepatitis WHO/ HIV/2017.06

2. Stanaway JD, Flaxman AD, Naghavi M, Fitzmaurice C, Vos T, Abubakar I, et al. The global burden of hepatitis from 1990 to 2013: finding from the Global Burden of Disease Study. Lancet 2016; 388(10049): 1081-88.

3. Jamil Z, Waheed Y, Malik M, DurraniAA. Effect of sofosbuvir plus ribavirin therapy on hepatitis $C$ patients in Pakistan: a retrospective study. Peer J 2018; 6(1): e4853.

4. Mansoor H, Masood MA, Siddique K, Badar F, Yusuf MA. Clinical features and survival of patients with hepatocellular carcinoma at a cancer treatment facility. Bio Med Res Thera 2019; 6(11): 3492-500.

5. Holmes JA, Thompson AJ. Interferon-free combination therapies for the treatment of hepatitis C: current insights. Hepat Med 2015; 7(1): 51-70.

6. Lam BP, Jeffers T, Younoszai Z, Fazel Y. The changing landscape of hepatitis $C$ virus therapy: focus on inter-feron-free treatment. Therap Adv Gastroenterol 2015; 8(5): 298-312.

7. AASLD-IDSA. HCV testing and linkage to care. Recommendations for testing, managing, and treating hepatitis C. Available from: http://www.hcvguidelines.org/full-report/hcv-testingand-linkage-care.

8. Epclusa (sofosbuvir and velpatasvir) tablets, for oral use. Full prescribing information. Foster city, CA: Gilead Sciences, Inc; 2016.

9. Feld JJ, Jacobson IM, Hezode C, Asselah T, Ruane PJ, Gruener N. Sofosbuvir and velpatasvir for HCV genotype 1,2,4,5, and 6 infection. N Eng J Med 2015; 373(27): 2599-607.

10. Foster GR, Afdhal N, Roberts SK, Brau N, Gane EJ, Pianko S, et al. Sofosbuvir and velpatasvir for HCV genotype 2 and 3 infection. N Eng J Med 2015; 373(27): 2608-17.

11. Yu JW, Wang GQ, Sun LJ, Li XG, Li SC. Predictive value of rapid virological response and early virological response on sustained virological response in $\mathrm{HCV}$ patients treated with pegylated interferon alpha-2a and ribavirin. J Gastroenterol Hepatol 2007; 22(6): 832-36.

12. Curry MP, O'Leary JG, Bzowej N, Muir AJ, Korenblat KM, Fenkel JM. Sofosbuvir and velpatasvir for HCV in patients with decompensated cirrhosis. N Eng J Med 2015; 373(27): 2618-28.

13. Agarwal K, Patel K, Samuel D, Bourliere M, Younes Z, Morgan $\mathrm{T}$, et al. SOF/VEL for 12 weeks results in high SVR12 rates in subjects with negative predictors of response to treatment: an integrated analysis of efficacy from the ASTRAL-1, ASTRAL-2 AND ASTRAL-3 studies. J Hepatol 2016; 64(2): S787-S8.

14. Lawitz E, Bourliere M, Han L, Mcnally J, Stamm L, Brainard D, et al. Treatment with SOF/VEL or SOF/VEL/VOX is well tolerated and results in high SVR12 in genotype 1-6 HCV infected patients with minimal fibrosis: a retrospective analysis of the ASTRAL and POLARIS clinical studies. J Hepatol 2017; 66(1): S310-S1.

15. Zignego AL, Monti M, Gragnani L. Sofosbuvir/Velpatasvir for the treatment of Hepatitis C Virus infection. Acta Biomed 2018; 89(3): 321-31.

16. Butt N, Muhammad I, Bakr A, Akhtar Z, Ali M, Muhammad SS, et al. Efficacy and safety of sofosbuvir-velpatasvir combination in hepatitis $C$ virus-infected Pakistani patients without cirrhosis or with compensated Cirrhosis: A Prospective, Open-label Interventional Trial. Cureus 2020; 12(1): e6537.

17. Chekuri S, Nickerson J, Bichoupan K, Sefcik R, Doobay K, Chang $\mathrm{S}$, et al. Liver stiffness decreases rapidly in response to 
successful hepatitis $C$ treatment and then plateaus. PLoS One 2016; 11(7): e0159413.

18. Castera L, Pinzani M, Bosch J. Non invasiveevaluation of portal hypertension using transient elastography. J Hepatol 2012; 56(3): 696-703.

19. Bureau C, Metivier S, Peron JM, Selves J, Robic MA, Gourraud PA, et al. Transient elastography accurately predicts presence of significant portal hypertension in patients with chronic liver disease. Aliment Pharmacol Ther 2008; 27(12): 1261-68.

20. Kazemi F, Kettaneh A, N'Kontchou G, Pinto E, Ganne-Carrie $\mathrm{N}$, Trinchet JC, et al. Liver stiffness measurement selects patients with cirrhosis at risk of bearing large oesophageal varices. J Hepatol 2006; 45(2): 230-35.

21. Shiffman M, Brau N, Bourgeois S, Mathurin P. The Tolerability of Sof/VEL for 12 Weeks in $>1000$ Patients Treated in the
ASTRAL-1, ASTRAL-2, and ASTRAL-3 Studies: An Integrated Safety Analysis. Gastroenterol 2016; 150(4): S1093-95.

22. Bertoli A, Sorbo MC, Aragri M, Lenci I, Teti E, Polilli E, et al. Prevalence of single and multiple natural NS3, NS5A and NS5B resistance-associated substitutions in Hepatitis $\mathrm{C}$ virus genotypes 1-4 in Italy. Sci Rep 2018; 8(1): 8988.

23. Chen $\mathrm{ZW}$, Li H, Ren H, Hu P. Global prevalence of pre-existing $\mathrm{HCV}$ variants resistant to direct-acting antiviral agents (DAAs): mining the GenBank HCV genome data. Sci Rep 2016; 6: 20310.

24. Pawlotsky JM. Hepatitis $C$ virus resistance to direct-acting antiviral drugs in interferon-free regimens. Gastroenterol 2016; 151(1): 70-86

25. Bourliere M, Gordon SC, Flamm SL, Cooper CL, Ramji A, Tong $\mathrm{M}$, et al. Sofosbuvir, velpatasvir, and voxilaprevir for previously treated HCV infection. N Engl J Med 2017; 376(22): 2134-46. 